\title{
HASTANE PNÖMATİK SİSTEMLERİNIN BULANIK MANTIKLA MODELLENMESİ
}

\begin{tabular}{|c|c|}
\hline \multicolumn{2}{|r|}{$\begin{array}{c}\text { Büşra Özgür }{ }^{1^{*}} \text {, Resul Kara' } \\
{ }^{1} \text { Düzce Üniversitesi, Bilgisayar Mühendisliği Bölümü, Düzce, Türkiye }\end{array}$} \\
\hline Anahtar Kelimeler & Öz \\
\hline $\begin{array}{l}\text { Pnömatik Taşıma, } \\
\text { Bulanık Mantık, } \\
\text { Hastane Pnömatik Sitemleri. }\end{array}$ & $\begin{array}{l}\text { Otomasyon, robotik ve hastaneler gibi oldukça geniş kullanım alanı olan; Pnömatik } \\
\text { sistemlerle ilgili hassas kontrol uygulamalarına yönelik çalışmalar giderek } \\
\text { artmaktadır. Ancak sistemin lineer olmayan ve karmaşı bir yapıya sahip olması, } \\
\text { sistemin kontrol edilmesini zorlaştırmaktadır. Sistemin davranışını belirlemek ve } \\
\text { verilen girişlere göre çıkışların ifade edilmesi için matematiksel modeller } \\
\text { kullanılmaktadır. Amaç sistemin davranışının öngörülmesi ve kontrolüdür. } \\
\text { Doğrusal sistemler için birçok kontrol teorisi varken, doğrusal olmayan } \\
\text { sistemlerde kontrol teorileri kısıtlıdır. Doğrusal olarak modellenemeyen sistemler } \\
\text { bulanık olarak modellenebilir. Böylece lineer olmayan sistemlerin kontrolleri daha } \\
\text { kolay bir şekilde sağlanmaktadır. Hastanelerde kullanılan pnömatik sistemler } \\
\text { sayesinde numune alınan odalar ile laboratuvar arasında zaman ve enerji } \\
\text { açısından büyük bir tasarruf sağlar. Hastane pnömatik sistemleri de lineer } \\
\text { olmayan bir yapıya sahiptir ve bulanık mantıkla modellenerek sistemin en verimli } \\
\text { şekilde kontrolü amaçlanmaktadır. Bu sayede hastane pnömatik sistemleri, daha } \\
\text { etkili bir şekilde kullanılabilecek, karşılaşlan problemlere daha kolay bir şekilde } \\
\text { çözüm bulunabilecek ve sistem verimliliği en üst seviyeye ulaşabilecektir. } 4 \text { giriş ve } \\
1 \text { çlkış parametresi kullanılarak bulanı mantıkla modellenen sistemin başarısı } \\
\text { yaklașık olarak \%90 (\%91,6) dır. }\end{array}$ \\
\hline
\end{tabular}

\section{FUZZY LOGIC MODELLING OF HOSPITAL PNEUMATIC SYSTEM}

\section{Keywords \\ Pneumatic Transport, \\ Fuzzy Logic, \\ Hospital Pneumatic Systems.}

\begin{abstract}
There are increasing studies for precise control applications related to pneumatic systems, which are widely used such as automation, robotics and hospitals. However, nonlinearity and complexity of the system make it difficult to control the system. Mathematical models are used to determine the behavior of the system and to express outputs according to given inputs. The aim is to control the system and to predict its behavior.

There are many control theories for linear systems, but these theories are few for nonlinear systems. Thus, nonlinear systems are more easily controlled. Thanks to the pneumatic systems used in the hospitals, a great saving in time and energy are ensured between the rooms and the laboratory. Hospital pneumatic systems have a nonlinear structure and they are modeled with fuzzy logic to control the system in the most efficient way. Pneumatic systems that are modeled with fuzzy logic can be used more effectively, solutions to the problems can be found more easily and system efficiency can be reached to the highest level. Modeled with fuzzy logic using 4 inputs and 1 output parameters, the success of the system is approximately $90 \%(91.6 \%)$.
\end{abstract}

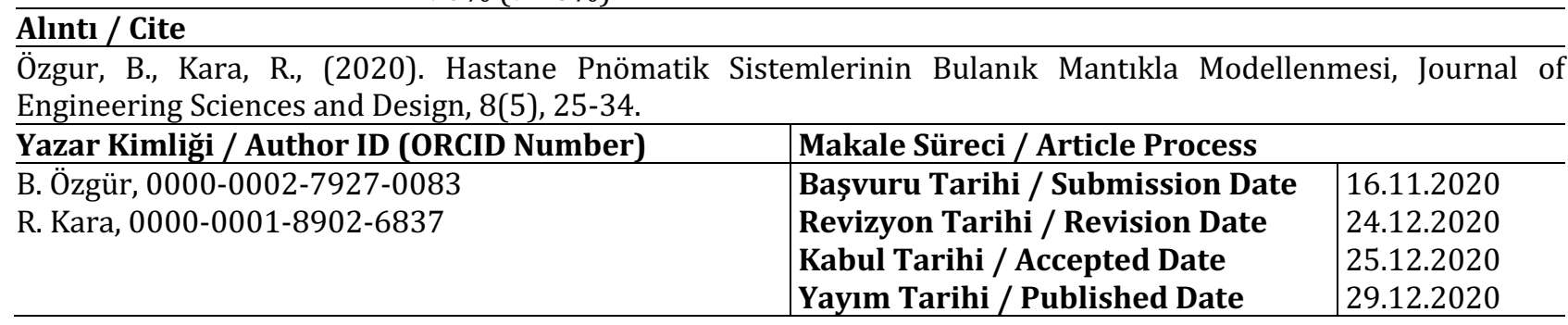

\footnotetext{
*ilgili yazar / Corresponding author: busratakgil@duzce.edu.tr, +90-380-542-1036
} 


\section{Giriș (Introduction)}

Kontrol sistemlerinin tasarımına sistemin matematiksel modelinin elde edilmesiyle başlanır. Fakat sistemler kompleks veya lineer olmayan bir yapıya sahip olduğunda, matematiksel olarak modellenmeleri zorlaşmaktadır. Ayrıca modellenecek bazı sistemlerin ayrıntılı bir matematik modeli mevcut değildir. Ya da sistem değişkenleri kesin olarak bilinmeyip, zamanla değișen ifadeler içerebilmektedir. Bu duruma çözüm olarak son yıllarda bulanık mantıkla geliștirilen kontrol sistemleri popülerlik kazanmıștır. Yapay zekâ alanındaki teknikler karmaşık ve doğrusal olmayan yapıdaki kontrol sistemleri için iyi bir çözüm olabilmektedir (Mamdami, 1974). Doğrusal olarak modellenemeyen sistemler uzman bir kişinin bilgi ve deneyimine dayanan bulanık mantıkla modellenebilmektedir. Böylece lineer olmayan sistemlerin kontrolleri daha kolay şekilde sağlanmış olacaktır. Uzman kişilerin deneyimleri sisteme aktarıldıktan sonra sistemin denetimi daha esnek bir yapıya sahip olabilmektedir.

Pnömatik sistemlerin enerji kaynağı olan, basınçlı hava dış ortamdan alınan atmosfer havasının bir kompresör ile belirli bir oranda sıkıștırılması ile elde edilmektedir. Elektrik enerjisinin olduğu her yerde elde edilebilen ve depolanabilir olması nedeniyle endüstride en çok tercih edilen enerji kaynaklarından birisidir. Basınçlı hava kolay elde edilip yaygın bir kullanıma sahip olmasına karşın oldukça pahalı bir enerji türüdür. Basınçlı hava kullanımı ve kompresörlerin enerji tüketimi verimlilik çalışmalarında dikkat edilmesi gereken unsurlar arasındadır (Saidur vd., 2010).

Enerji ihtiyacının güvenilir, ekonomik ve yeterli bir biçimde karşılanabilmesi sistemlerin verimliliği için oldukça önemlidir. Enerji verimliliği, harcanan enerji miktarının, üretimdeki kapasite ve kaliteyi azaltmadan en aza indirilmesidir (Frigerio ve Matta, 2015). Pnömatik sistemlerde enerji verimliliği ise, pnömatik iş elemanlarında kullanılan havanın gerektiği kadar basınçlandırılması, şartlandırılması ve tüketilmesi esasına dayanmaktadır (Zaim ve Aras, 2020). Bu çalışmada, endüstride yaygın olarak kullanılan basınçlı havayla çalışan hastane pnömatik sistemlerindeki enerji verimliliğini sağlamak amacıyla sistem bulanık mantıkla modellenmiştir. Hastane pnömatik taşıma sistemlerinde kullanılan kompresörlerin basıncının daha verimli şekilde kullanılmasıyla enerji tasarrufu sağlanması amaçlanmaktadır.

\section{Literatür Çalışması (Literature Survey)}

Pnömatik taşıma sistemleriyle ilgili çeşitli çalışmalar bulunmasına rağmen, hastane pnömatik taşıma sistemlerinin bulanık mantıkla modellenmesine ilişkin çalışmalar oldukça sınırlıdır. Bulanık kontrolörlerin, kontrol zorluklarını çözmek için kullanıldığı birçok çalışma bulunmaktadır. Bu çalışmalarda pnömatik sistemlerde boru çapı-hava hızı-basınç değerleri arasında bağlantılar kurarak iletim kapasitesine ulaşmaya çalışılmıştır. Taşıma kapasitesi ve iletim mesafesi arasındaki ilişkiyi kullanarak pnömatik taşıyıcının performans değerlendirmeleri yapılmıştır.

Otomasyon, robotik ve hastaneler gibi oldukça geniş kullanım alanı olan; pnömatik sistemlerle ilgili hassas kontrol uygulamalarına yönelik çalışmalar giderek artmaktadır. Ancak sistemin lineer olmayan ve karmaşık bir yapıya sahip olması sistemin kontrol edilmesini zorlaştırmaktadır

Literatürde pnömatik sistemlerle ilgili yapılan çalışmalar genellikle pnömatik silindirlerin konum kontrolü üzerine yoğunlaşmıştır. Havanın sıkıştırılabilir özelliği nedeniyle kontrol için konum ve hız ölçümlerinin yanı sıra basınç ölçümü de gerekebilir. Basınç ölçümü hız ölçümüne göre daha basit gerçekleştirilmesi sebebiyle, basınç ölçümlerine dayalı kontrol uygulamaları daha caziptir ve daha ucuz bileșenlerin kullanımına imkân sağlar (Kuzucu vd., 2015).

Pnömatik sistemlerle ilgili yapılan diğer çalışmalarda ise pnömatik sistem tasarımının optimum hale getirilmesi amaçlanmıştır. Bunlardan bazıları şu şekildedir: Simulink kullanılarak pnömatik sistem simülasyonu yapılmış, doğrusal bir pnömatik hareketlendirici sistemin parametre değişimlerine tepkisi incelenmiştir (Akkaya vd., 2011). Bulanık mantık ile pnömatik sistemlerin bir arada kullanıldığı başka bir çalışmada hassas konum kontrolü yapılmıştır. Deneysel bir sistem üzerinde daha önce geçerliliği sınanmış matematiksel model kullanılarak benzetim yapılmıştır. Çalışma sonucunda bulanık mantık konum kontrolü başarımının; basınç ve konum ölçümünün hassas kontrolünde yeterli olduğu ve hız ölçümüne gerek kalmadığı sonucuna varılmıştır (Kuzucu vd., 2003). J. Wang, ve J.Pu makalelerinde pnömatik motorlu bir sistemin modellemesini yapay sinir ağ 1 yardımıyla gerçekleştirmiştir.( Wang vd., 1998). L. Shi ve N. Sepehri pnömatik pistonun hareket kontrolü için adaptif yapay sinir ağı tabanlı bulanık kontrolör tasarlamışlardır (Shi vd., 2004). R. Marumo, O. M. Tokhi ise pnömatik motorun matematiksel modeline ihtiyaç duyulmadan yapay sinir ağıyla kontrol gerçekleştirmişlerdir (Marumo vd., 2004). 
Yapılan başka bir çalışmada ise pnömatik sistem modelinin optimizasyonu genetik algoritma kullanılarak yapılmıştır (Um vd., 2003). Gang Yang ve arkadaşları ise pnömatik basınç kontrolü için pozitif ve negatif basınç altında çalışabilen bulanık pid kontrol sistemi oluşturmuşlardır (Yang vd., 2017). Yapmış olduğumuz çalışma literatürdeki çalışmaları destekler niteliktedir ve pnömatik taşıma sistemlerinin özelleşmiş bir dalı olan hastane pnömatik sistemleri için önemli bir öngörü sunmaktadır.

\section{Material and Method}

\section{1. Önerilen Metot (Proposed Method)}

Endüstride sıklıkla kullanılan ikincil enerji kaynağı basınçlı havadır. Pnömatik sistemler basınçlı havayı enerji kaynağı olarak kullanmaktadırlar (Zaim ve Aras, 2020). Katıların bir gaz akışında pnömatik taşınması; endüstriyel alanın yanı sıra bankalar, süpermarketler, hastaneler gibi birçok alanda kullanılmaktadır. Pnömatik taşımanın temel avantajları: esneklik sağlaması, yüksek değerli ürünlerin nakliyesinde güvenlik, otomasyon / kontrol kolaylığı ve düşük bakım maliyetleridir. Pnömatik olarak taşınabilen malzeme aralığı da oldukça geniştir. Kâğıt, madeni para, kan numuneleri, ilaçlar, yedek parçalar gibi. Bununla birlikte, pratik sınırlamalar nedeniyle, mevcut sistemlerin çoğunluğu, esasen taşınan birim kütle başına yüksek güç talebi nedeniyle, 1000 m'den az mesafelerde saatte 1 ila 400 ton arasında değișen kapasitelere sahiptir (Barbosa vd., 2011).

Hastane pnömatik sistemleri ise hastane organizasyonunu daha efektif hale getirmek, verimliliği artırmak için güvenli ve hızlı bir yol sağlar. Bu sistemlerde tahlil numuneleri insan gücü olmaksızın pratik bir şekilde taşınabilmektedir. Sistem temel olarak hastane içinde dolaşan tüpler, gönderici alıcı istasyonlar ile kontrol merkezinden oluşur. Bu sistemde taşıyıcı içindeki numuneler yatay ve dikey olarak odalar, katlar hatta binalar arasında saniyede yaklaşık 6-7 m/sn lik bir hızla hareket ederler. Bu hareketin kaynağına; sisteme gerekli havayı sağlayan basınçlandırma ünitesi (kompresör/blower unit) adı verilir.

Şekil 1'de hastane pnömatik sistemlerin temel yapısı gösterilmiştir. Sistem kompresör, taşıyıcı tüpler, borular (taşıma hattı), istasyonlar, yönlendiriciler ve bilgisayar kontrol biriminden oluşmaktadır. Hastanenin büyüklüğüne göre genişleyebilen bir yapıya sahiptir. Alıcı veya gönderici istasyonlar arasında numunelerin iletimi sağlanmaktadır. Sistemin enerji kaynağı kompresörlerdir.

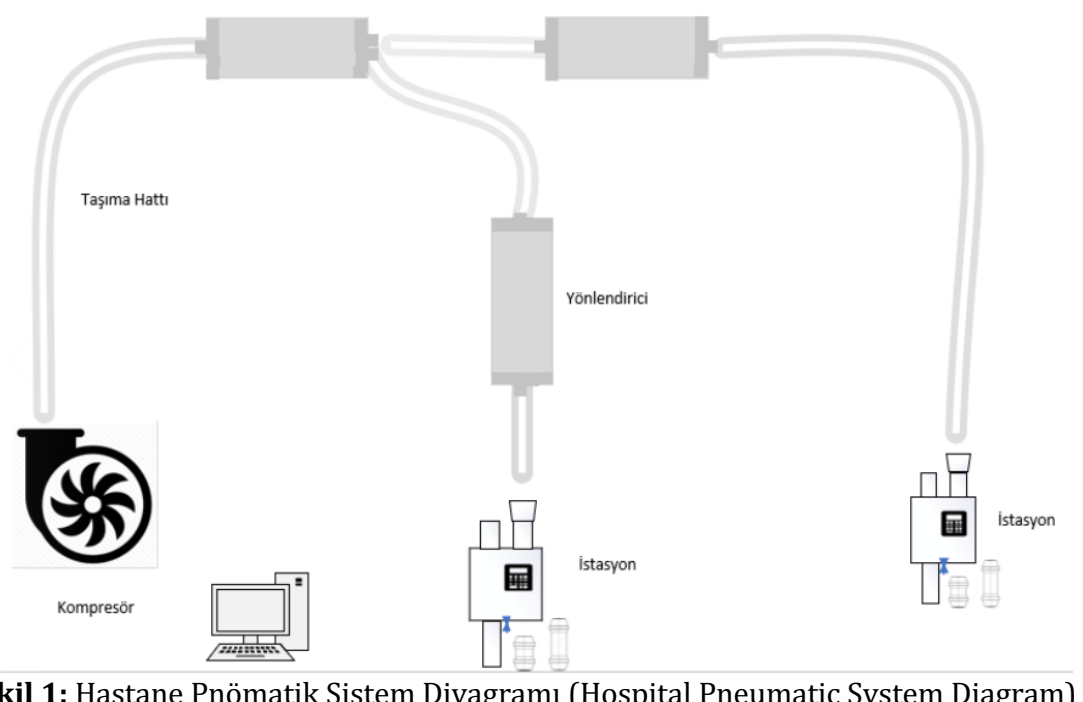

$\mathrm{Bu}$ çalışmanın temel amacı sistemin enerji kaynağı olan kompresörlerin daha verimli ve etkin bir şekilde kullanılmasıdır. Sistemin enerji kaynağı olan kompresörlerin her bir taşıma esnasında her durumda sabit ve belirli bir enerjide çalışması yerine sistemin ihtiyacına göre yeterli basıncı sağlaması amaçlanmaktadır. Bunun sebebi yüksek basınç, yüksek enerji tüketimi ve maliyetin artması demektedir. Bu yüzden basınçlı hava sistemleri tasarlanırken basınç kaybını minimize etmek için çalışılmaktadır.

Sistemlerin davranışını belirlemek ve verilen girişlere göre çıkışların ifade edilmesi için matematiksel modeller kullanılmaktadır. Doğrusal sistemler için birçok kontrol teorisi varken, doğrusal olmayan sistemlerde kontrol 
teorileri kısıtlıdır. Bulanık mantıkla modelleme doğrusal ve doğrusal olmayan sistemleri etkili bir şekilde ifade edebilmektedir. Doğrusal olarak modellenemeyen sistemler bulanık olarak modellenebilir. Böylece lineer olmayan sistemlerin kontrolleri daha kolay bir şekilde sağlanmaktadır. Hastanelerde kullanılan pnömatik sistemler sayesinde numune alınan odalar ile laboratuvar arasında zaman ve enerji açısından büyük bir tasarruf sağlar. Hastane pnömatik sistemleri de lineer olmayan bir yapıya sahiptir ve bulanık mantıkla modellenerek sistemin en verimli şekilde kontrolü amaçlanmaktadır. Bu sayede hastane pnömatik sistemleri, daha etkili bir şekilde kullanılabilecek, karşılaşıllan problemlere daha kolay bir şekilde çözüm bulunabilecek ve sistem verimliliği en üst seviyeye ulaşabilecektir.

Bulanık mantık kavramı Prof. Lotfi Zadeh ile ortaya çıkmıştır. Klasik matematiksel yöntemlerle modellenemeyen karmaşık sistemler için iyi bir alternatif sunmaktadır. Bulanık mantık matematiksel tanımlamalar yerine niteliksel tanımlama olanağı sağlar. Kompleks ve belirsiz sistemlerde nicel ve nitel bilgilerin kapsamlı olarak değerlendirilmesi gerekir. Bulanık mantık kompleks sistemlerin kontrolünde kural tabanlı bir yöntem sağlar. Bulanık mantığın geleneksel kontrol yöntemlerine göre avantajları şunlardır: gürültüye veya diğer bozulmalara karşı sağlamlık gösterir, ekonomiktir, kullanıcı deneyimlerinin kullanılmasına olanak sağlar Bulanık mantığın bir başka önemli özelliği, doğal bir dile benzer dilsel sıfatlar ve karşllıklı ilişkiler kullanan ifadeler kullanmasıdır. Bu durum, bulanık mantık tabanlı bir denetleyicinin anlaşılmasını ve değiştirilmesini geleneksel kontrol teknikleriyle mümkün olandan çok daha kolay hale getirir (Kumbla vd., 1994).

$\mathrm{Bu}$ çalışmada enerji verimliliği, hastane pnömatik taşıma sistemlerinde kullanılan kompresör basıncının bulanık kontrolüyle sağlanması amaçlanmaktadır. Standart çalışma esnasında tüp sisteminde yaklaşık 6-7 m/sn hızla hareket etmektedirler. Ancak hassas malzemelerin taşınması gibi farklı durumlarda bu hız 2-3 m/sn olarak düzenlenmesi gerekebilir. Kontrollü taşıma laboratuvar materyallerinin, kan vb. örneklerin hasar görmeden sorunsuz bir şekilde iletilmesini sağlar. Bu da ancak hız kontrolüyle mümkündür. İletim hattında taşınacak malzemeye göre hızının ayarlanması ve verimli bir șekilde güç tüketilmesini sağlamak amacıyla sistem belirli giriş ve çıkış parametrelerine göre tasarlanmıştır. Giriş parametreleri seçilirken şimdiye kadar yapılan çalışmalar temel alınmıştır.

Pnömatik sistem tasarımında yüksek hızlar ve iletilecek malzemenin özelliği tasarımda önemli parametrelerdir. İletim hattı boyutları ihtiyaç duyulan güç ile orantılıdır. (Azeloğlu, 2006).

Sistem tasarımı yapılırken göz önüne alınması ilgili olarak şu tavsiyelerde bulunulmuştur:

(i) Basınçlı hava hatları tasarlanırken minimum basınç kaybı olacak şekilde doğru hat tasarımı yapılmalıdır.

(ii) Tasarım sürecinde pnömatik iş elemanları doğru seçilmeli, olması gerekenden fazla itme kuvveti gerektirecek ürünler enerji tüketiminin artmasına sebep olacağından düşük enerji tüketimi sağlayacak elemanlar seçilmelidir. Örnek vermek gerekirse ISO 15552 pnömatik silindirlerde bir alt çapa geçilmesiyle ortalama \%30 oranında daha az hava tüketilmektedir (Zaim ve Aras, 2010).

\subsection{Sistem Parametreleri (System Parameters)}

Sistemin modellenmesi Matlab'da yer alan "Fuzzy Logic Toolbox" kullanılarak yapılmıştır. Bu araç probleme uygun bulanık çıkarım metodunu sunmaktadır. Tablo 1'de sistemin giriş ve çıkış parametreleri verilmiştir. Giriş parametrelerinin seçiminde literatürdeki çalışmalar göz önüne alınarak; sistemin performansını en çok etkileyen parametreler seçilmiştir. Sistem modelinde giriş ve çıkış parametrelerinin değer aralıkları hastane pnömatik sistemlerinde kullanılan malzemelerin katalog bilgileri göz önüne alınarak seçilmiştir.

Tablo 1: Bulanık Modelin Giriș ve Çıkıș Parametreleri (Fuzzy Model Input and Output Parameters)

\begin{tabular}{|c|c|l|l|}
\hline \multicolumn{2}{|c|}{} & \multicolumn{2}{|c|}{$\begin{array}{c}\text { PARAMETRE DEĞER } \\
\text { ARALIKLARI }\end{array}$} \\
\cline { 2 - 4 } & MíN & MAX \\
\hline \multirow{4}{*}{$\begin{array}{c}\text { GíRİŞ } \\
\text { PARAMETRELERİ }\end{array}$} & $\begin{array}{c}\text { Taşıma Yönüı̈ Etkisi } \\
\text { (etki eden sürtünme) }\end{array}$ & 0 & 100 \\
\cline { 2 - 4 } & Malzeme Ağırlığı (gr) & 1 & 100 \\
\hline \multirow{2}{*}{$\begin{array}{c}\text { ÇIKIŞ } \\
\text { PARAMETRELERİ }\end{array}$} & Basınç (mBar) & 1 & 1 \\
\hline
\end{tabular}


Şekil 2'de tasarlanan modelin blok görünümü verilmiştir. Modelde dört giriş parametresi ve bir çıkıș parametresi bulunmaktadır. Şekil 3'de ise Düzce Üniversitesi Hastanesinde kullanılan pnömatik taşıma sisteminin bir bölümü gösterilmektedir. Şekilde kompresör ve faklı tiplerde taşıyıcılar bulunmaktadır.

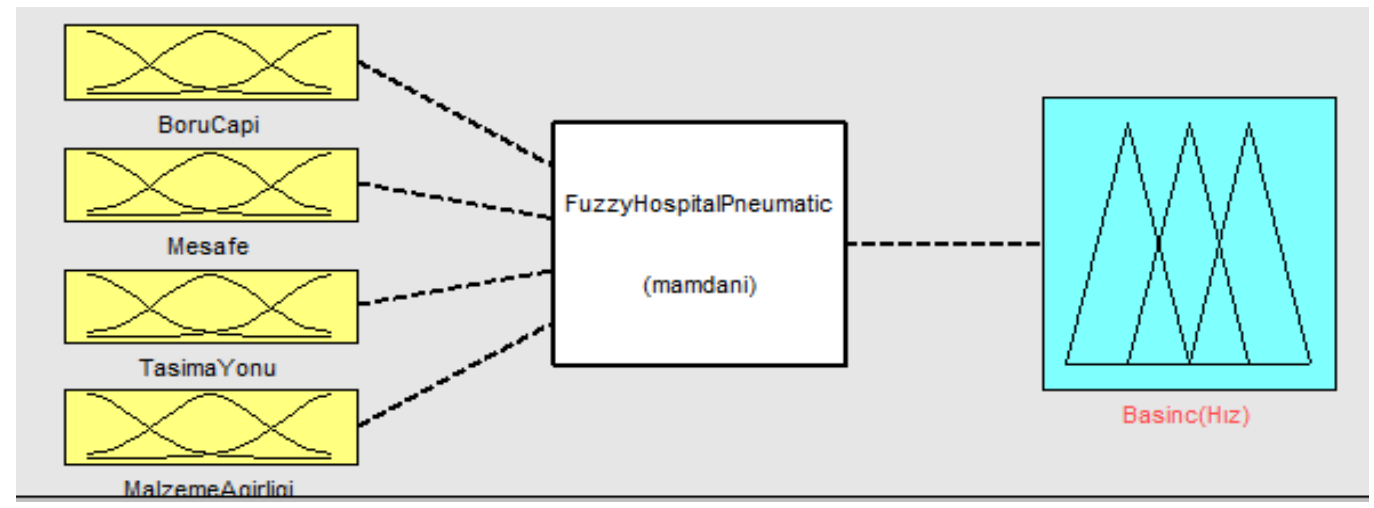

Şekil 2: Sistem Bulanık Modeli (Fuzzy Model of the System)

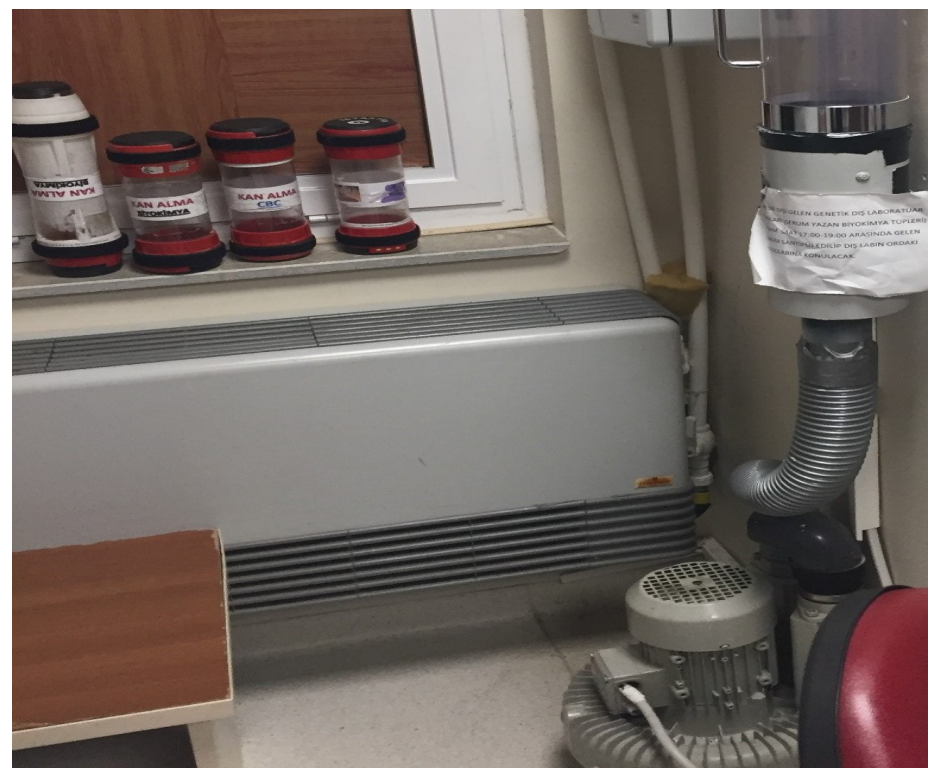

Şekil 3: Pnömatik Taşıma Sistemi Kompresör ve Taşıyıcılar (Pneumatic Conveying System Compressor and Carriers)

Sistemin düzgün bir şekilde çalışabilmesi için uygun boru çapı seçimi önemlidir. Boru çapı arttıkça iletim için gerekli güç artmaktadır. Boru çapı değerlerine göre üyelik fonksiyonu aşağıda gösterilmiştir. Boru seçiminde küçük boru çapı seçimi akış hızının artmasına dolayısıyla basınç düşümüne sebep olacağı, büyük boru çapı seçiminin ise hava kaybına sebep olabileceği göz önünde bulundurulması gerekir. Boru çapının sisteme etkisinin bulanıklaștırılmasında kullanılan dilsel ifadeler; dar orta ve geniş olarak 3 tiptedir. Şekil 4'de üyelik fonksiyonları verilmiştir.

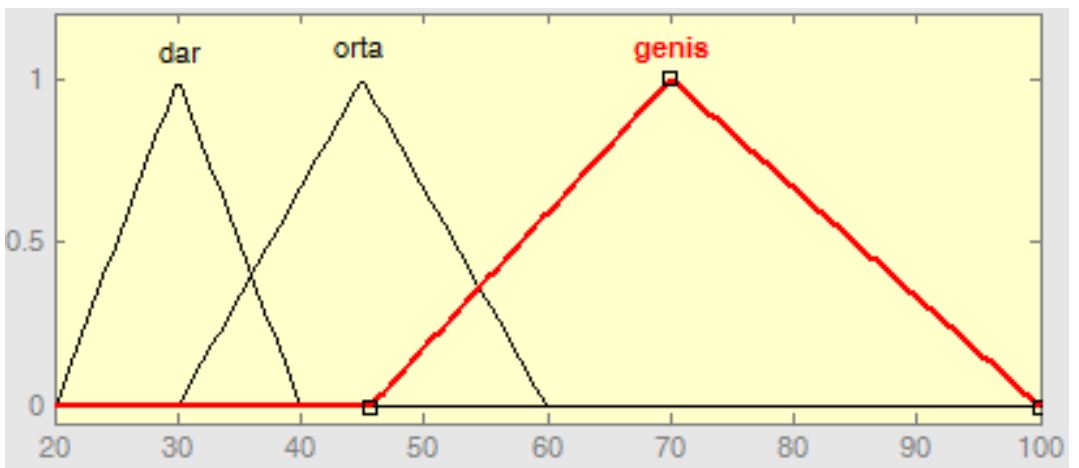

Şekil 4: Boru Çapı Girişine Ait Üyelik Fonksiyonları (Membership Functions of the Pipe Diameter Input) 


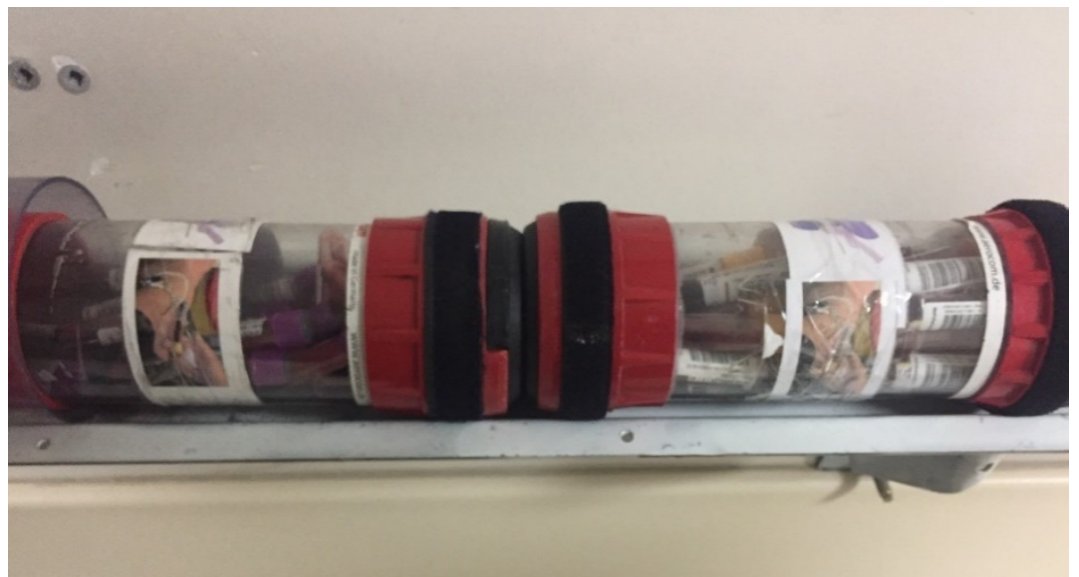

Şekil 5: Kan Numunelerine Ait Taşıyıcı Sistem Elemanları (Carrier System Components of Blood Samples)

Şekil 5'de pnömatik taşıma esnasında kan numuneleri için kullanılan taşıyıcılar gösterilmektedir. Taşınacak malzemeye göre taşıyıcı boru çapı değişmektedir.

Güç tüketimini etkileyen diğer önemli unsur taşıma mesafesidir. Hastanelerde pnömatik sistem boru hatları genellikle kolon-kiriş șemasına uygun olarak döșenir. Hastane büyüklüğüne göre boru hattının büyüklüğü değişmektedir. Basınç kaynağı ile istasyonlar (pnömatik numunelerin gönderildiği veya alındığı uç noktalar) arasındaki mesafe arttıkça iletim için gerekli güç artmaktadır. Şekil 6'te mesafe üyelik fonksiyonları yer almaktadır. Modellenen sistemde 0-100 m aralığında pnömatik taşıma gerçekleşmektedir.

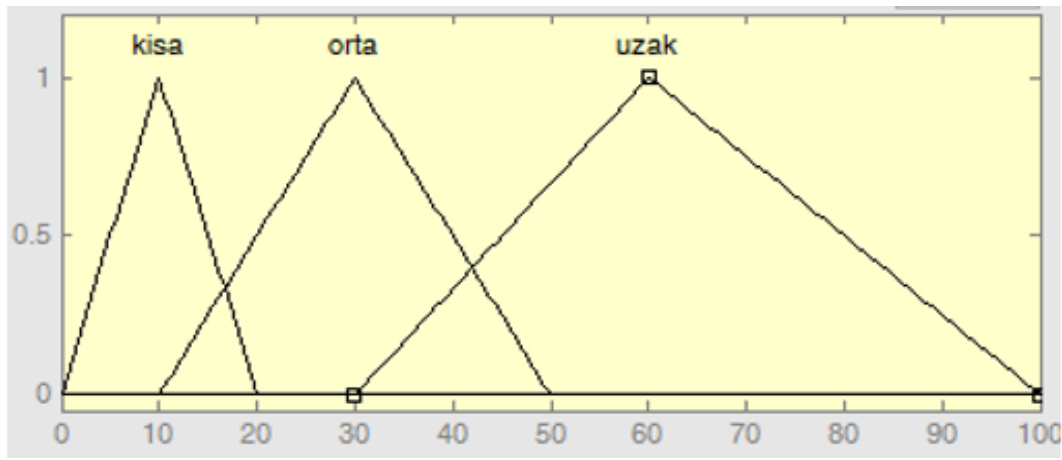

Şekil 6: Mesafe Girişine ait Üyelik Fonksiyonları (Distance Membership Functions)

Pnömatik tüpler aracılığıyla kan numuneleri, ilaçlar, belgeler, röntgen filmleri gibi farklı ağırlıktaki materyaller taşınabilir. Örneğin kan numuneleri hafif malzeme ağırlığı grubunda değerlendirilirken; patoloji numuneleri ağır malzeme grubunda değerlendirilmektedir. Taşınan malzeme ağırlı̆̆ının artması gerekli güç tüketimini de arttırmaktadır. Malzeme ağırlığının sisteme etkisini ifade eden üyelik fonksiyonları Şekil 7'de verilmiştir.

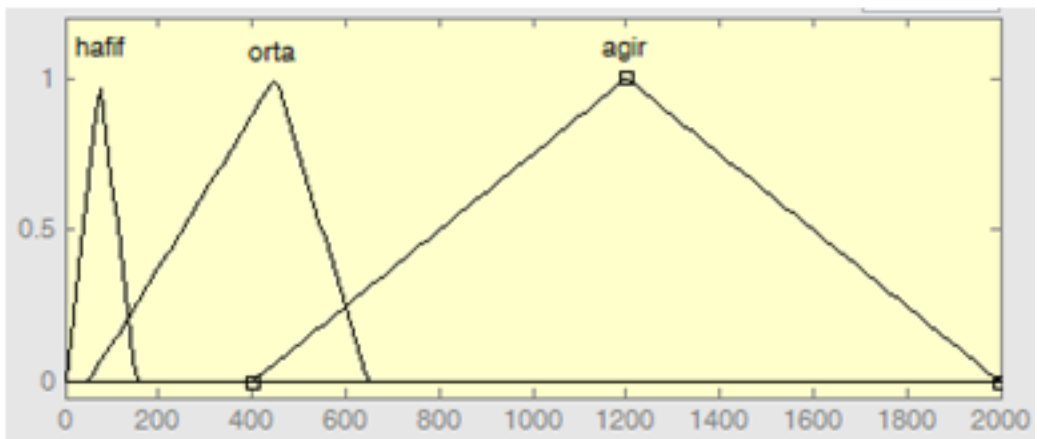

Şekil 7: Malzeme Ağırlığı Girişine ait Üyelik Fonksiyonları (Material Weight Membership Functions)

Yatay durumdaki bir taşıyıcıyı harekete geçirmek için gereken basınç dikey taşımada olduğuna göre daha farklı ve azdır. Dönüş yönlerinde dirseklerde ise bu durum biraz daha farklıdır. Taşıma yönüne etki eden en önemli unsurlardan biri dirseklerde(dönemeç) meydana gelen geçişlerdir. Bozulmaların çoğu bu kısımlarda meydana gelir. Bu durumlarda taşınan nesneye etkiyen sürtünme kuvveti göz önüne alınarak değer aralıkları seçilmiştir. Malzeme taşınması için dikey yönde taşıma en fazla güç gerektirir. Pnömatik taşıma esnasında oluşabilecek 
taşıma yönünü etkileyen örnek boru dizaynı şekil 8’te gösterilmiştir. Dikey, Yatay ve ara yönlerde (dirseklerde) taşıma parametreleri; bu şema göz önüne alınarak oluşturulmuştur. Şekil 9 ise farklı taşıma yönlerine sahip örnek boru hattını göstermektedir. Şekil 10'da taşıma yönüne ait üyelik fonksiyonları yer almaktadır.
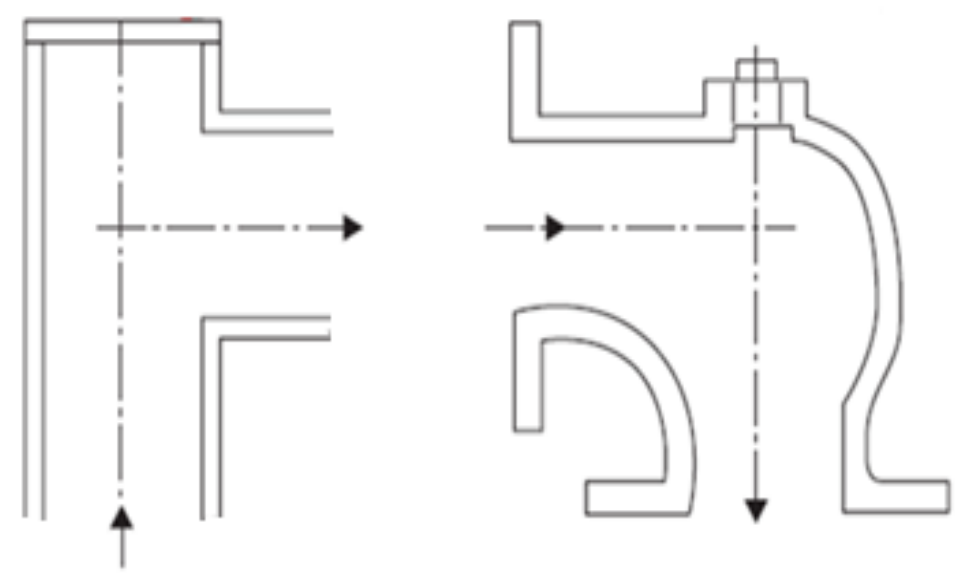

Şekil 8: Örnek Boru Tasarımı (Example Pipe Design)

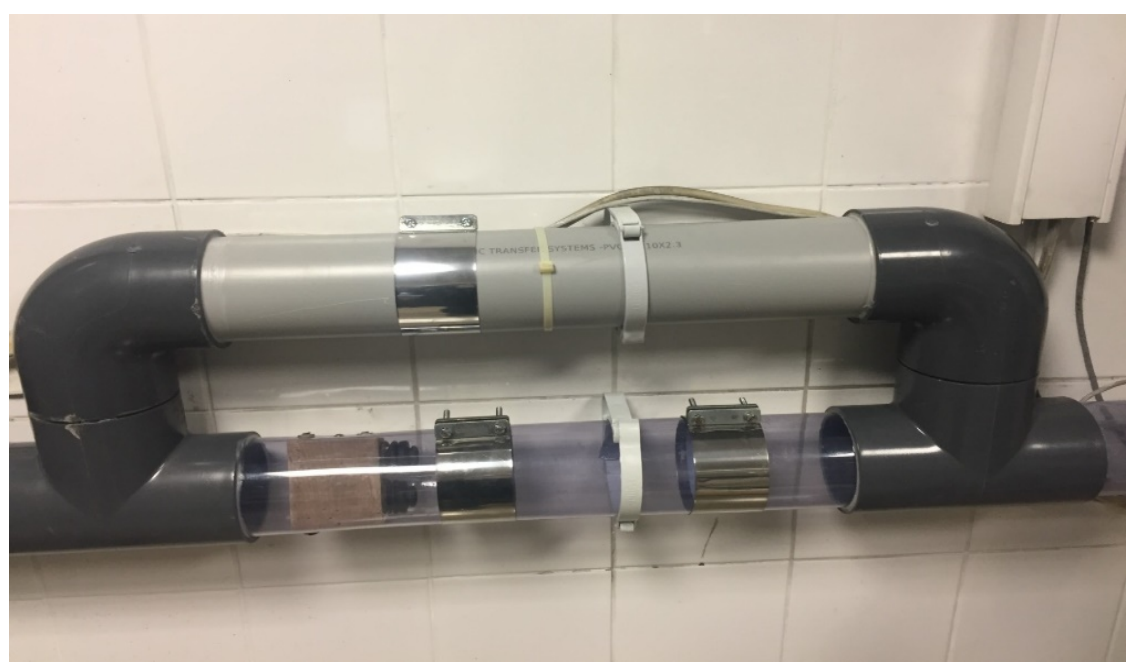

Şekil 9: Farklı Taşıma Yönlerine Sahip Örnek Boru Hattı (Pipeline with Different Transport Directions)

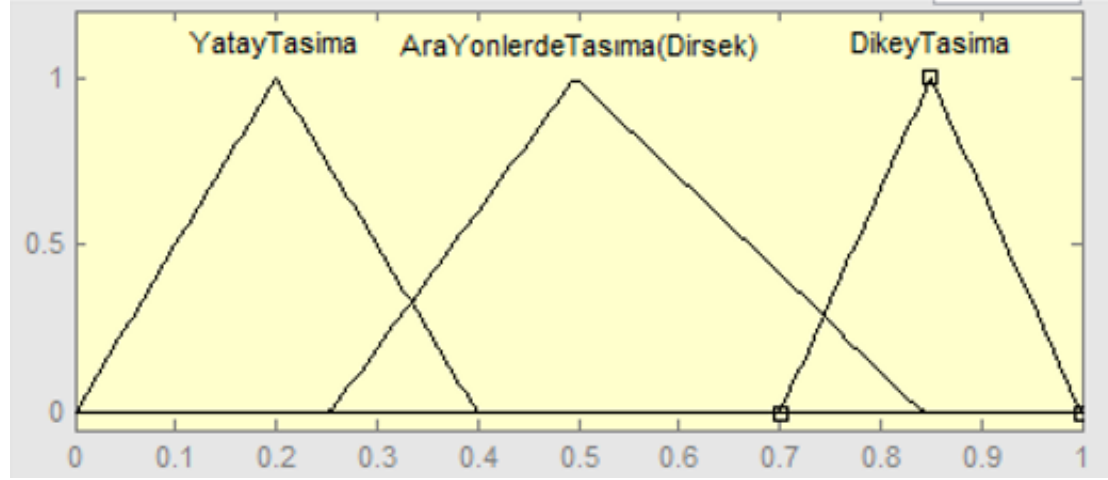

Şekil 10: Taşıma Yönü Girişine ait Üyelik Fonksiyonları (Transport Direction Membership Functions)

Atmosferdeki havayı sıkıștırarak basınçlı hava üreten, mekanik enerjiyi pnömatik enerjiye dönüștüren makinelere kompresör adı verilir. Kompresörlerin kapasitesi debi ve çıkış basıncı türünden ifade edilir. Bu parametre harcanan güçle iliş̧kili olarak üretilen basınç ile taşınan malzemelerin hızını belirlemektedir. Yüksek basınçlı sistemlerde az miktardaki havayla büyük miktarlarda materyal iletimi gerçekleștirilir. Genellikle küçük çaplı borular kullanılır. Düşük basınçlı sistemler ise basıncın az olması sebebiyle kısa mesafeler ve küçük materyal debileri için uygundur (Kiliçkan ve Güner,2006). Pnömatik devrelerin belirli bir optimal çalışma basıncı vardır. Sistemin ihtiyacından daha fazla uygulamam yüksek bir basınç enerji kaybına ve aşınmalara sebep olurken, sistemin ihtiyaç duyduğu değerden daha düşük bir basınç ise istenilen işlevin yerine getirilmemesine 
veya verimin düşmesine sebep olabilmektedir. Şekil 11'de basınç parametresine ait üyelik fonksiyonları yer almaktadır.

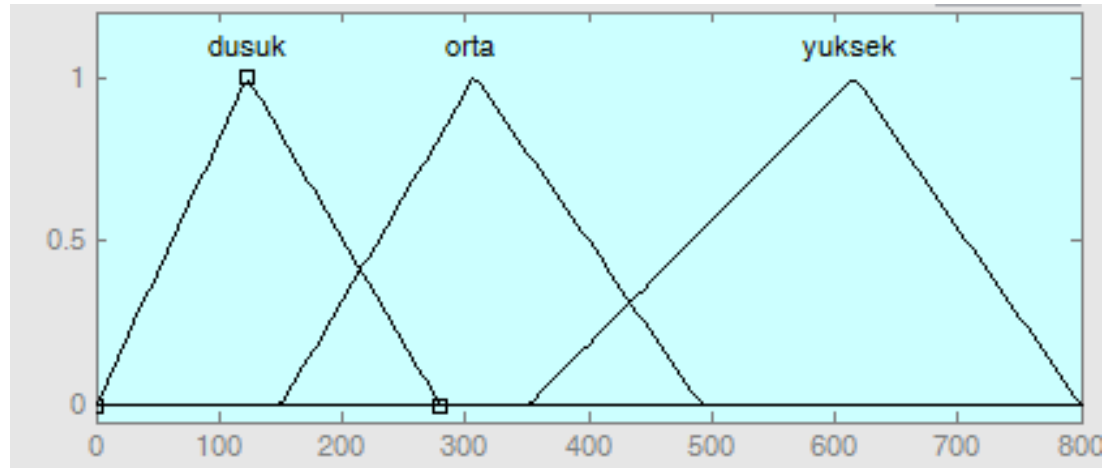

Şekil 11: Başınç Çıkış Parametresine ait Üyelik Fonksiyonları (Pressure Membership Functions)

Yapılan çalışmada kural tablosu oluşturulup seçilen giriş parametrelerine göre harcanan kompresörün üretmesi gereken basınç hesaplanmaktadır. Bulanık model oluşturulurken giriş parametrelerinin üyelik fonksiyonlarının

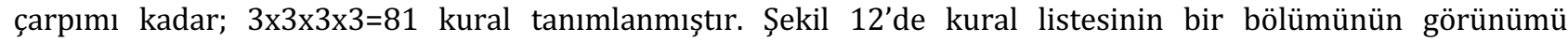
verilmiştir.

1. If (BoruCapi is Dar) and (Mesafe is KIsa) and (TasimaYonu is YatayTasima) and (MalzemeAgirligi is Hafif) then (Basinc(HIz) is DusukBasinc) (1)

2. If (BoruCapi is Genis) and (Mesafe is Uzak) and (TasimaYonu is DikeyTasima) and (MalzemeAgirligi is Agir) then (Basinc(Hiz) is YuksekBasinc) (1)

3. If (BoruCapi is Dar) and (Mesafe is Uzak) and (TasimaYonu is AraYonlerdeTasıma(Dirsek)) and (MalzemeAgirligi is Agir) then (Basinc(HIz) is YuksekBasinc) (1)

4. If (BoruCapi is Genis) and (Mesafe is Uzak) and (TasimaYonu is YatayTasima) and (MalzemeAgirligi is Hafif) then (Basinc(HIz) is DusukBasinc) (1)

5. If (BoruCapi is Orta) and (Mesafe is Kisa) and (TasimaYonu is YatayTasima) and (MalzemeAgirligi is Agir) then (Basinc(HIz) is OrtalamaBasinc) (1)

6. If (BoruCapi is Dar) and (Mesafe is KIsa) and (TasimaYonu is AraYonlerdeTasıma(Dirsek)) and (MalzemeAgirligi is Orta) then (Basinc(HIz) is OrtalamaBasinc) (1)

7. If (BoruCapi is Orta) and (Mesafe is Uzak) and (TasimaYonu is DikeyTasima) and (MalzemeAgirligi is Hafif) then (Basinc(HIz) is OrtalamaBasinc) (1)

8. If (BoruCapi is Dar) and (Mesafe is Uzak) and (TasimaYonu is AraYonlerdeTasma(Dirsek)) and (MalzemeAcirligi is Agir) then (Basinc(Hiz) is YuksekBasinc) (1)

Şekil 12: Kural Listesinde Yer Alan İlk Sekiz Kuralın Görünümü (View of the First Eight Rules in the Rule List)

Kurallar oluşturulduktan sonra durulaştırma sonucu ortaya çıkan yüzey eğrisi Şekil 13’ de gösterilmiştir. Şekilde malzeme ağırlığı ve taşıma yönüne göre basınç değişimi görülmektedir. Yüzeye etki eden sürtünme kuvvetinin az olduğu taşıma yönlerinde sistem basıncının daha düşük olduğu görülmektedir. Malzeme ağırlığının ve yüzeye etki eden sürtünme kuvvetinin belirli değerlerin üzerine çıması basınç artışına sebep olmaktadır.

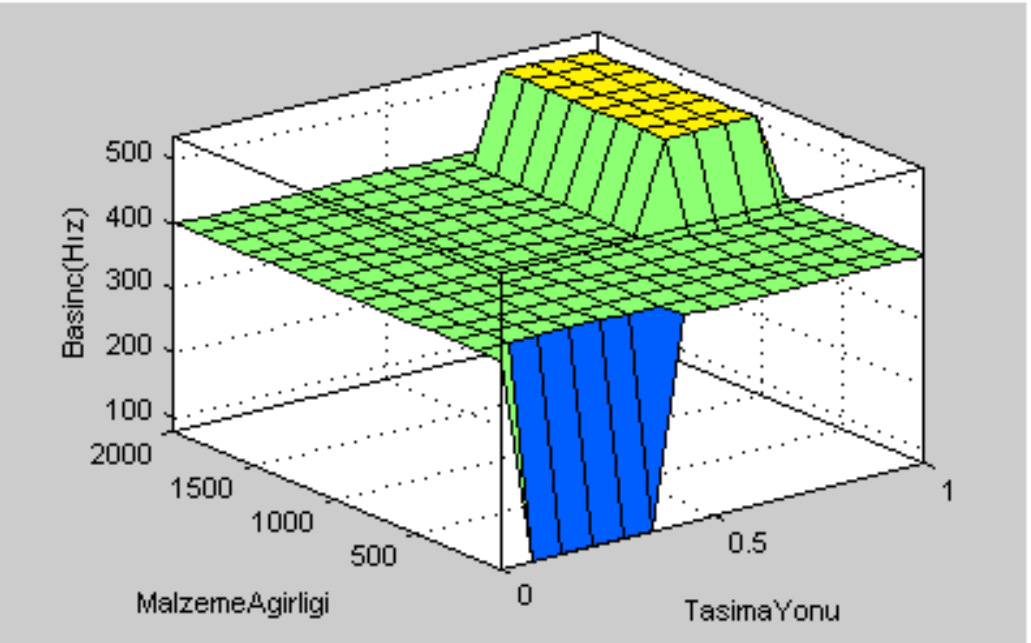

Şekil 13: Malzeme Ağırlı̆̆ Ve Taşıma Yönüne Göre Basıncın Yüzey Görünümü (Surface View of Pressure According to Material Weight and Transport Direction)

\subsection{Sistem Parametreleri Arasındaki İlişki (Relationship Between System Parameters)}

Değișkenler arasındaki ilișkinin derecesini ve yönünü belirlemek amacıyla korelasyon matrisleri kullanılmıştır. Bu ilişkiyi değerlendirebilmek için -1 ile +1 arasında değerler alan Pearson katsayısı kullanılmaktadır. İncelenen parametrelerin birbirleriyle olan korelasyon katsayıları Tablo 2'de gösterilmiştir. Elde edilen sonuçlara göre 
basınç ve boru çapı parametreleri arasında +0, 914985 değeriyle pozitif yönlü kuvvetli bir ilişki olduğu görülmektedir. Diğer parametrelerin korelasyon katsayılarının düşük seviyede olduğu gözlemlenmiştir. Bu durum değişkenler arasında güçlü doğrusal bir ilişki olmadığını göstermektedir. Ayrıca basınç ile taşıma yönü parametresi arasında negatif yönlü bir ilişki olduğu görülmektedir.

Tablo 2: Sistem Parametreleri Korelasyon Matrisi (System Parameters Correlation Matrix)

\begin{tabular}{|c|c|l|l|l|l|}
\hline & Boru Çapı & \multicolumn{1}{|c|}{ Mesafe } & Taşıma Yönü & $\begin{array}{c}\text { Malzeme } \\
\text { Ağırlı̆̆ }\end{array}$ & Basınç \\
\hline Boru Çapı & 1 & & & & \\
\hline Mesafe & $-0,01911$ & 1 & & & \\
\hline Taşıma Yönü & $-0,09559$ & 0,052842 & 1 & & \\
\hline $\begin{array}{c}\text { Malzeme } \\
\text { Ağırlı̆̆ı }\end{array}$ & 0,118139 & 0,037434 & 0,092037 & 1 & \\
\hline Basınç & 0,914985 & 0,285 & $-0,03275$ & 0,099406 & 1 \\
\hline
\end{tabular}

\section{Deneysel Sonuçlar (Experimental Results)}

Hastane pnömatik sistemlerinde kullanılan sistemlerin basınç kaynağı olan kompresörlerin bulanık mantıkla modellenmesine dayanan çalışma sonuçları, hastane pnömatik sistem uzman kişileriyle yaplan görüşmeler sonucunda elde edilen verilerle karşıllaştırılmıștır. Çalışma sonucunda elde edilen sonuçlar hastane pnömatik sistem uzmanlarıyla yapılan görüşmeler sonucunda elde edilen verilerle karșılaștırılmıștır. Sistemin lineer olmayan bir yapıya sahip olması sebebiyle matematiksel olarak modellenememiştir ve daha önceki çalışmalarda aynı parametreleri kullanan bir çalışma bulunmadığından elde edilen sonuçların karşılaştırılması yapilamamıştır.

Tablo 3: Bulanık mantıkla modellenen sistemin ürettiği sonuçlar ile uzman kişi değerlerinin karşılaştırılması (Comparison of the results produced by the system modeled with fuzzy logic and the expert person values)

\begin{tabular}{|c|c|l|l|l|l|}
\hline $\begin{array}{c}\text { BORU } \\
\text { ÇAPI(mm) }\end{array}$ & MESAFE(m) & $\begin{array}{c}\text { TAŞIMA YÖNÜ } \\
\text { ETKISİ (ETKİ EDEN } \\
\text { SÜRTÜNME) }\end{array}$ & $\begin{array}{c}\text { MALZEME } \\
\text { AĞIRLIĞI(GR) }\end{array}$ & BASINÇ(MBAR) & $\begin{array}{c}\text { UZMAN KIŞ̦i } \\
\text { BASINÇ DEǴERI } \\
\text { (MBAR) }\end{array}$ \\
\hline 28 & 50 & 0,5 & 1400 & 532 & 500 \\
\hline 85 & 100 & 0,1 & 100 & 401 & 400 \\
\hline 31 & 56 & 0,321 & 1009 & 400 & 350 \\
\hline 92 & 24 & 0,84 & 508 & 450 & 500 \\
\hline
\end{tabular}

Tablo 3 bulanık mantıkla modellenen sistemden elde edilen sonuçlar ile uzman kişi tarafından belirlenen değerlerin karşılaştırmalarını göstermektedir. Bu sonuçlara göre, bulanık mantıkla modellenen sistem uzman kişilerin değerlerine yakın değerler üretmeyi başarmıştır. Sistemin genel başarı yüzdesi \%91 olarak hesaplanmıştır. Modellenen sistemin giriș parametrelerinin ara değerler aldığı durumlarda daha başarılı, sınır değerlerde ise başarı yüzdesinin daha az olduğu görülmüștür. Bundan sonraki çalışmalarda modellenen sistemin daha iyi sonuçlar üretebilmesi için; veri seti arttırılabilir, giriş parametrelerinin üyelik fonksiyon türleri ve sayıları değiştirilebilir.

\section{Sonuç (Result)}

Bu çalışmada pnömatik taşıma sisteminde kompresörlerin güç tüketiminin kontrolüne yönelik bir yöntem önerilmiş, sistemin modellenmesi yapılmıştır. Sistem parametreleri bulanıklaştırma ve durulaştırma işlemlerine tabi tutularak sonuçlar elde edilmiștir. Giriş parametrelerinin etkileri bir araya getirilerek sistem modellenmiştir. Hastane pnömatik sisteminin etkin ve verimli bir şekilde çalışmasılyla ilgili en önemli unsur, taşınan malzemenin en uygun hava hızıyla taşınmasını sağlamaktır. Basınçlı havayla çalışan pnömatik sistemlerdeki enerji verimliliği sağlamak amacıyla tasarlanan kontrol sistemi bulanık bir yapıya dayanır. Kontrolör girişleri: Boru Çapı, Mesafe, Taşıma Yönü Etkisi, Malzeme Ağırlı̆̆ı; çıkış parametresi olarak ise kompresörün üretmesi gereken basınç değeridir.

İlgili çalışmalar incelendiğinde birçok alanda olduğu gibi pnömatik taşıma sistemlerinde de enerji tasarrufu büyük bir önem arz etmektedir. Hastane pnömatik sistemleri için enerjinin verimli kullanımı amacıyla sistemin ihtiyacı göz önüne alınarak, en düşük enerji tüketimine sahip kompresör/blower seçimi yapılmalıdır. Kompresör işletme basıncı mümkün olduğunca düşük tutulmalıdır. Çalışmanın bu duruma önemli bir katkı sağlaması 
beklenmektedir. Ayrıca ayarlanabilir hızlarda iletim, enerji tüketiminde verimlilik sağlamasının yanı sıra hastanelerde hassas numunelerin güvenli bir şekilde ve bozulmaya uğramadan taşınabilmesine katkı sağlamaktadır.

Bulanık mantık doğrusal olmayan sistemlerin kontrolünde iyi bir alternatif olarak karşımıza çıkar. Bu yaklaşım sayesinde uygulamalar basitleşir, hız kazanır ve maliyet azalır. Ancak tasarlanan sistem aynı zamanda bulanık yaklaşımın olumsuz yönlerini de içinde barındırır. Üyelik fonksiyonlarının ve kural tabanının belirlenmesinde kesin, belirli kurallar yoktur. Deneme yanılma yöntemi ise zaman almaktadır. Sistemin öğrenme yeteneği yoktur ve sistem performansı uzman görüşüne bağlı olarak değişmektedir. Bu olumsuzlukları gidermek amacıyla sonraki çalışmalarda üyelik fonksiyonlarının seçimiyle ilgili olarak genetik algoritma kullanılması ve aynı sistemin yapay zekâ yöntemleriyle modellenerek elde edilen sonuçların karşılaștırılması planlanmaktadır.

\section{Çıkar Çatış̧ması (Conflict of Interest)}

Yazarlar tarafından herhangi bir çıkar çatışması beyan edilmemiştir. No conflict of interest was declared by the authors.

\section{Kaynaklar (References)}

Akkaya, Ali Volkan, et al, 2011. Simulink kullanarak bir pnömatik sistemin simülasyonu. Doğuş Üniversitesi Dergisi ,6.2 (s.155-162).

Barbosa, Paulo Roberto, and Paulo Seleghim Jr.,2011. On the Application of Fuzzy Logic Control in Pneumatic Conveying systems. Journal of the Brazilian Neural Network Society, 9.4, 256-265.

Frigerio, N., Matta, A., 2015. Energy-Efficient Control Strategies for Machine Tools With Stochastic Arrivals. IEEE Transactions on Automation Science and Engineering.

Kiliçkan, A., Güner, M. ,2006. Pneumatic conveying characteristics of cotton seeds. Biosystems Engineering, 95.4: 537-546.

Kumbla, Kishan Kumar, and Mo Jamshidi, 1994. Control of robotic manipulator using fuzzy logic. In Proceedings of 1994 IEEE 3rd International Fuzzy Systems Conference, pp. 518-523. IEEE.

Kuzucu, Et Al. ,2015. Pnömatik Silindirlerde Basınç Geri Beslemesi ile Hassas Konum Kontrolü.

Kuzucu, Karaca, Benlıgırayoglu, 2003. Pnömatik Silindirlerde Basınç Geri Beslemesi İle Hassas Konum Kontrolü. III. Ulusal Hidrolik Pnömatik Kongresi Ve Sergisi.

Mamdani, E. H., 1974. Application of fuzzy algorithms for control of simple dynamic plant. Proceedings of the Institution of Electrical Engineers, 121(12).

Marumo, R. Tokhi, O. M., 2004. Intelligent Modeling and Control of a Pneumatic Motor, IEEE.

Saidur, R., Rahim, N.A., Hasanuzzaman, M., 2010. A review on compressed air energy use and energy savings, Renewable and Sustainable Energy Reviews 14, p.1135-1153.

Shi, L., Sepehri, N., 2004. Adaptive Fuzzy-Neural-Based Multiple Models for Fault Diagnosis of a Pneumatic Actuator. American Control Conference Boston, Massachusetts.

Um, T., Joo, Y., Kong, Y., Chun, I., Kim, S., \& Bang, J., 2003. Optimization of design parameters of a pneumatic system for solid freeform fabrication system using genetic algorithm. In Proceedings of 2003 IEEE Conference on Control Applications, Vol. 1, pp. 120-123. IEEE.

Wang, J.; PU, J.; Moore, P. R.; Zhang, Z., 1998. Modeling study and servo-control of air motor systems. Int. J. Control, Vol.71, No. 3, 459-476.

Yager, R. R., \& Filev, D. P., 1994. Essentials of fuzzy modeling and control. New York, 388, 22-23.

Yang, Gang, et al., 2017. Asymmetric fuzzy control of a positive and negative pneumatic pressure servo system. Chinese Journal of Mechanical Engineering, 30.6 ,1438-1446.

Zaim A., H. Aras, 2020. Pnömatik Sistemlerde Enerji Verimliliği. Engineer and Machinery, vol. 61, no. 698, p. 31-45, Review Article. 